Journal of trends in Computer Science and Smart technology (TCSST) (2020)

Vol.02/ No. 02

Pages: 89-97

https://www.irojournals.com/tcsst/

DOI: https://doi.org/10.36548/jtcsst.2020.2.003

\title{
Long Term Evolution -Self Organizing Network for Minimization of Sudden Call Termination in Mobile Radio Access Networks
}

\author{
Dr. M. Duraipandian, \\ Head of Department, Department of Computer Science and Engineering, \\ Vivekanandha College of Technology for Women, \\ Namakal, India. \\ Email: svsduraipandian@gmail.com
}

\begin{abstract}
Nowadays the mobile devices have become a more vital requisite and very crucial portion of our lives daily routine. The sudden call termination that happens unexpectedly (call drops) is a circumstance were the enduring calls get cut without any prior indication. The evolution of the services associated with the $3 \mathrm{G}$ and the $4 \mathrm{G}$ based on the voice and the data has ended up in high conflicts between the companies of the telecommunication to increase the consumer rate leading to major occurrence of the termination in the calls. Such abrupt un-notified call cessation still remains as an unanswered question in the telecommunication industry all over the world. Manifold measures and the researches put forth to devise the solution to the issue of un-notified call cessation for the mobile radio access networks were not successful as every methodology had its own advantages and as well as disadvantages. The laid out research made efforts to discover the reasons that for this un-notified sudden termination of calls, and examines the problem related with the termination of calls in each phase of the radio technology and puts forth the Self Organizing Network in the LTE for minimizing the factors that are related to the call termination and enhances the quality of the voice calls. Further brings down the expenses on the capital and the operations on terms of structural and the configuration attributes.
\end{abstract}

Keywords: Long Term Evolution, Self-Organizing Networks, Call Termination, Mobile Radio Access Network, Telecommunication

\section{Introduction}

Nowadays the mobile phone are gaining a high predominance in the lives of the human. As man is a social animal who need to communicate and be communicated the mobile phone has become critical portion in his daily routine. The daily activities of a human becomes remains meaningless and desolate. The mobile devices enables us to have an immediate communicate with our closest ones irrespective of time and place.

ISSN: 2582-4104 
Journal of trends in Computer Science and Smart technology (TCSST) (2020)

Vol.02/ No. 02

Pages: 89-97

https://www.irojournals.com/tcsst/

DOI: https://doi.org/10.36548/jtcsst.2020.2.003

Though the mobile service provide a seamless communication in most of the cases, in certain areas and in certain situations the strength of the signal become weak and enable only a broken voice communication or even terminate the call un-intimated. When the user undertakes a travel from one place to another, signals of the network do not perfectly assist as there are different network stand ups laid along the way affecting the smooth conveyance of the enduring call to the cells nearby.

This causes the sudden termination of the conversation. For this the "Telecom Regulatory Authority of India" as a remedy to the sudden un-notified call terminations devised an "interactive voice response" to record the feedback of the consumers regarding the quality of the call. The outcomes were observed and shared with the vendors of the telecom industry to analyze the issue and sort it out instantly. The "interactive voice response" framed was only capable of gathering the live information and was not proficient enough to deliver a solution. The researches made by "Telecom Regulatory Authority of India" found out that the infrastructure of the telecommunication does not cope with the customer rate as daily hundreds of new customers get added to a communication network and utilize the network. It becomes necessary that the infrastructure gets updated in order to handle the traffic load of the radio access network and the hand overs smoothly heightening the consumer trust over the telecom vendors.

The sudden un-intimated call ending influences the quality of the service and as well as the experience in the rural as well as the urban areas. Due to the digital division, the calls are affected by the improper transfer made to the nearby cells. The "Telecom Regulatory Authority of India" even performed the tests to dig out the reasons for the dropped calls. The calls drop as they do not depend on the algorithm, devising and procedure could not be a lifelong remedy for the reducing the drops in the call. The termination of call eradicates the quality in the service and increases the billing cost for the consumer as well as the infrastructure and the maintenance cost for the vendors. Few reasons gathered by the "Telecom Regulatory Authority of India" is listed in the Table.1

So the paper lays out the architecture of the Self-Organizing Network set up with the long term evolution, and many future technologies. Initially the Self-Organizing Network was set up with the 3GPP as well as the NGMN, recently multitudes of networks are continually spending time in the researching the methodologies to enhance the Self-Organizing Network. The Self-Organizing Network are regulated automatically by the formulating the objective functions and optimizing using the optimization algorithms. This practically minimizes the interference caused in the signal and improves the voice quality and as well as reduce the capital, infrastructure and the maintenance cost and regulate the parameters of the network as per the necessity.

ISSN: 2582-4104 
Journal of trends in Computer Science and Smart technology (TCSST) (2020)

Vol.02/ No. 02

Pages: 89-97

https://www.irojournals.com/tcsst/

DOI: https://doi.org/10.36548/jtcsst.2020.2.003

\begin{tabular}{|c|c|}
\hline Reasons & Description \\
\hline Weak Coverage & $\begin{array}{l}\text { There are some areas where signal strength is very feeble } \\
\text { because of tunnels, high mountains, in-building areas. } \\
\text { Resulting in usage of unlicensed boosters that cause } \\
\text { interference in the signal }\end{array}$ \\
\hline High Radio Traffic & $\begin{array}{l}\text { Radio traffic rises on the occasion of the festival, and there } \\
\text { is no infrastructure developed so far to control that situation. } \\
\text { Resulting in poor voice quality and call drop. }\end{array}$ \\
\hline Cells Overlap & $\begin{array}{l}\text { Cells overlap is also an important factor of call drop. } \\
\text { Whenever different cells overlap with each other and unable } \\
\text { to handle handover, the call would be dropped }\end{array}$ \\
\hline Congestion on Network & $\begin{array}{l}\text { New subscribers are added fast by the telecom service } \\
\text { provider, but less focus is being paid on increasing } \\
\text { infrastructure. Thereby, operating existing infrastructure is } \\
\text { taking place at the threshold level and the resultant call drop } \\
\text { factors increases and reduces the customer trust on network. }\end{array}$ \\
\hline During Traveling & $\begin{array}{l}\text { The subscriber gets call drop while roaming because one } \\
\text { cell passes the ongoing call to another cell. During this } \\
\text { process, if a neighbor cell having the weak signals and } \\
\text { coverage area, the call drop occurs. }\end{array}$ \\
\hline Weather & $\begin{array}{l}\text { Mobile signals cannot be impacted by the wind, but rain is a } \\
\text { killer of mobile signals, because water has the power to } \\
\text { block the radio signals between the mobile tower and your } \\
\text { cell phone. }\end{array}$ \\
\hline Hardware Issues & $\begin{array}{l}\text { The hardware issue is a major concern in the mobile era. } \\
\text { Subscriber rate is increasing rapidly, but the updated towers } \\
\text { with robust technology are not maintaining by vendors. So } \\
\text { the compatibility between cell phone and towers is not } \\
\text { working appropriately. }\end{array}$ \\
\hline
\end{tabular}

Table.1 Reasons for Call Drop

ISSN: 2582-4104 
Journal of trends in Computer Science and Smart technology (TCSST) (2020)

Vol.02/ No. 02

Pages: 89-97

https://www.irojournals.com/tcsst/

DOI: https://doi.org/10.36548/jtcsst.2020.2.003

\section{Related Works}

"Telecom Regulatory Authority of India" [1] performed testing periodically in various areas and measured the parameters of the network to bring out the reasons behind the dropped calls utilizing various tools and software's some of the reason listed by the "Telecom Regulatory Authority of India" for the dropping of the calls and the percentage of the occurrences are irregular behavior of the users $36.889 \%$ Abnormal network responses by $8 \%$ electromagnetic causes by $51 \%$ and other by $4 \%$

Shiokawa, et al [2] put forth the "Call admission scheme based on estimation of call dropping probability in wireless networks." Li, et al [3] devised "A dynamic channel assignment scheme for TDMA-based multihop cellular networks." Balapuwaduge, et al [4] performed a "Channel assembling with priority-based queues in cognitive radio networks: Strategies and performance evaluation." Monica, C. H et al [5] conducted the "A bandwidth degradation technique to reduce call dropping probability in mobile network systems."

Moysen, et al [6] conducted "A bandwidth degradation technique to reduce call dropping probability in mobile network systems." Lobinger,et al [7] devised Coordinating handover parameter optimization and load balancing in LTE self-optimizing networks." Pandian, M. Durai et al [8] presented the "Enhanced Network Selection and Handover Schema for Heterogeneous Wireless Networks."

Jennifer S. Raj. et al [9] conducted the Self-organizing hierarchical structure for wireless networks." G. Josemin Bala et al [10] performed the Stab-WIN: Self organized, topology control ability backbone node in wireless networks." Jyothirmai, Pondi, et al [11] presented the "Secured self-organizing Computing Structures for Future Wireless Personal Networks" and devised the "DDOS Attack Detection in Telecommunication Network Using Machine Learning" network architecture in wireless personal networks." Smys, S et al [12] and et al [13] has elaborated the "Innovative

\section{Proposed Work}

To develop a human intervention reduced operations and automatic optimization of the parameters of the network the self-organized network becomes necessary for the LTE. Incorporating the self-organizing network into the LTE would lessen the manual efforts and optimize the parameters based on the necessity heightening the service experience quality and minimizing the expense. The diagram below in figure. 1 depicts the self-organizing network in the long term evolution.

ISSN: 2582-4104 
Journal of trends in Computer Science and Smart technology (TCSST) (2020)

Vol.02/ No. 02

Pages: 89-97

https://www.irojournals.com/tcsst/

DOI: https://doi.org/10.36548/jtcsst.2020.2.003

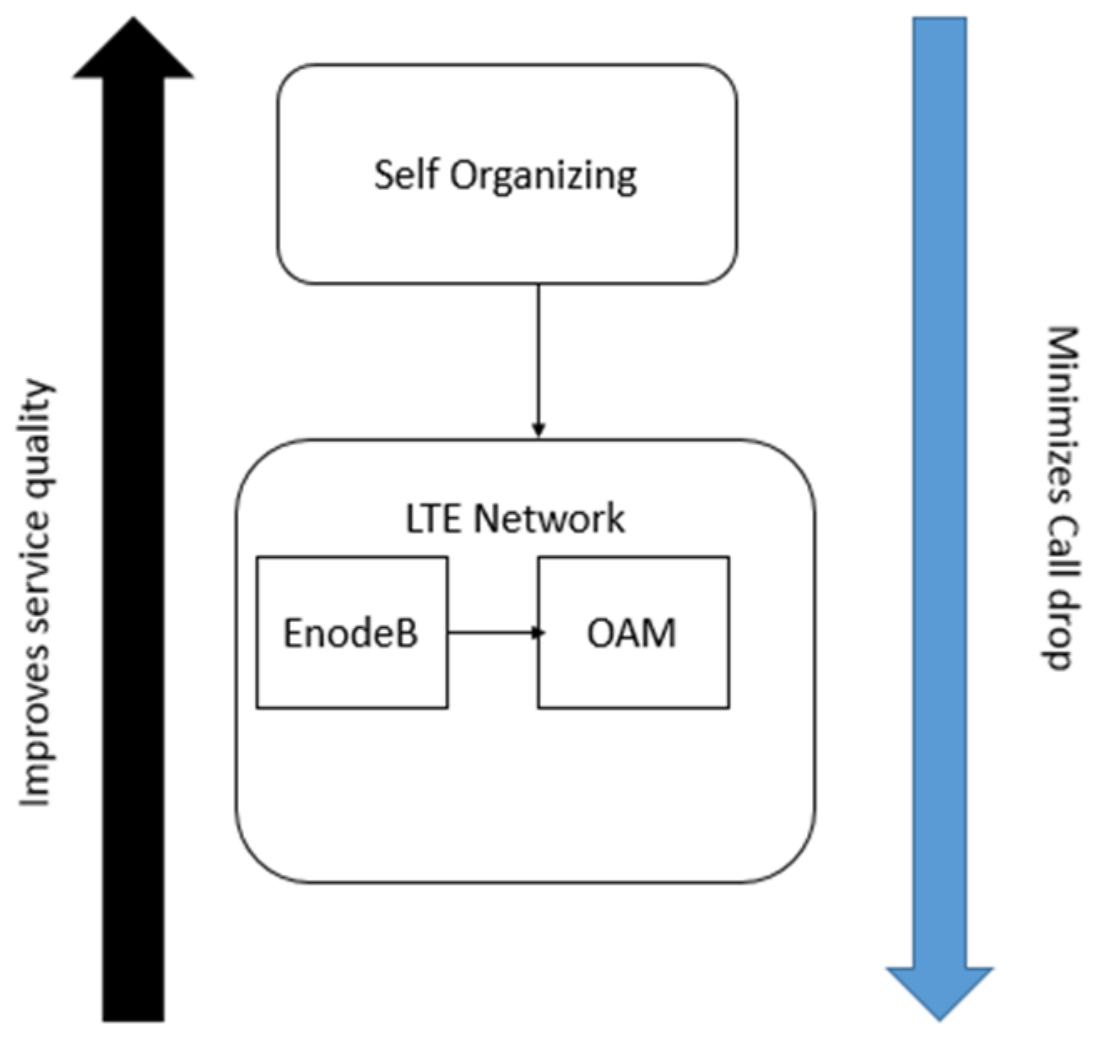

Figure.1 Self-Organizing Network in the Long Term Evolution

The scheme is presently built using the Future generation wireless network and could be updated further with the upcoming radio technologies. The "Self -Organizing" networks are regulated by triple reliable operations that is the reconfiguring on its own, optimizing without outside intervention and capability of "self-healing" the corresponding optimization algorithm based on the heuristics and the metaheuristics are engaged in to automatically optimize the parameters according to the user needs. The reconfiguring process configures the freshly set up nodes utilizing the automated procedure to identify the fundamental parameters and take in the necessary software for performing the fundamental operations and the automated regaining from the failures caused. 
Journal of trends in Computer Science and Smart technology (TCSST) (2020)

Vol.02/ No. 02

Pages: 89-97

https://www.irojournals.com/tcsst/

DOI: https://doi.org/10.36548/jtcsst.2020.2.003

The "self-optimization" procedure takes in the algorithms for optimizing the "coverage and capacity" interference, mobility, load balancing etc. so the parameters get optimized according to the demand without human intervention.

The "Self-healing" enables the network to take in the fault diagnosing software's and hardware components and automatically identifies the cell outage and the recovery without human intervention. The Self organizing networks in the LTE as shown in the figure. 1 is set up into the OAM and the eNodeB, or in either locations, positioning the self-organizing networks make them centralized, or distributed or hybrid.

The centralized S-O networks are deployed only in the OAM, whereas distributed are deployed in the eNode $\mathrm{B}$ and in hybrid the S-O Network is positioned in both. In case of the hybrid the OAM hold the complicated portion of the algorithm and the eNodeB holds the portion that is easy. But compared to the three structure the hybrid seems to be more flexible. The figure.2 (a, b, c) represents the three categories of the S-O network.
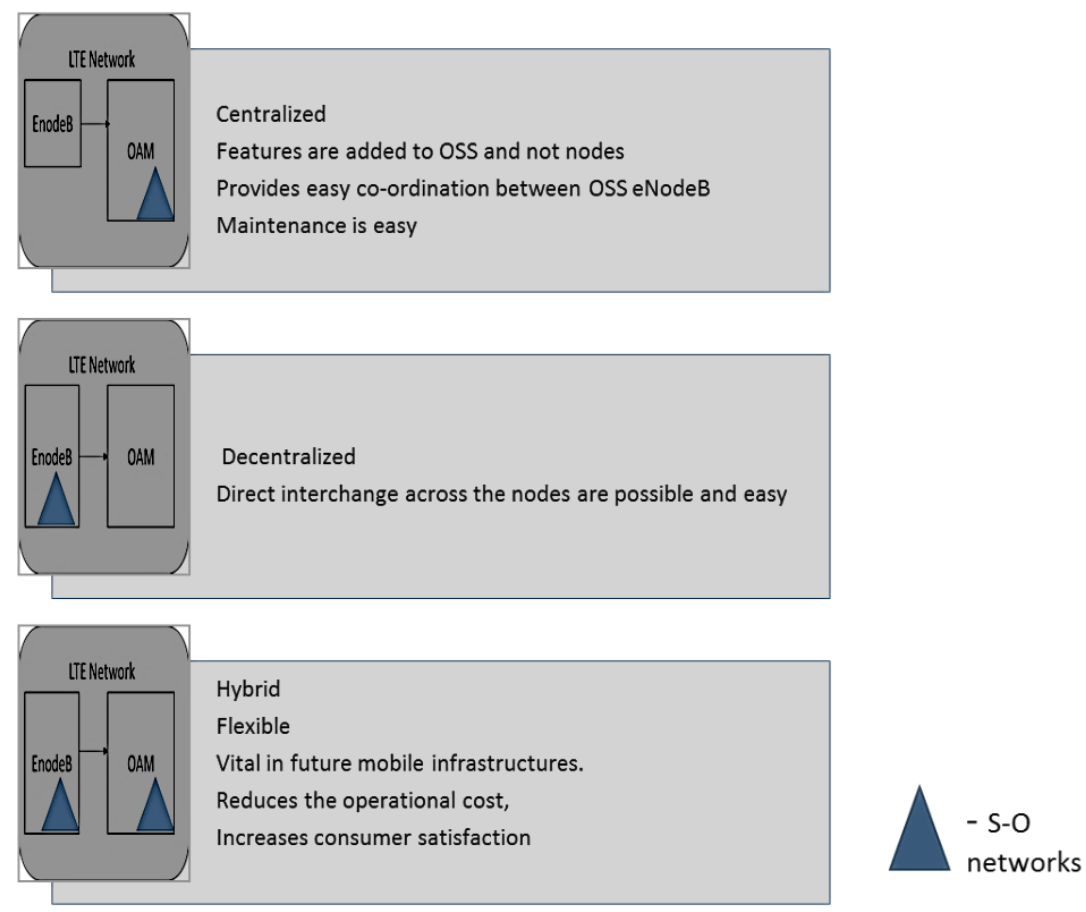

Figure.2 Categories of S-O network.

ISSN: 2582-4104 
Journal of trends in Computer Science and Smart technology (TCSST) (2020)

Vol.02/ No. 02

Pages: 89-97

https://www.irojournals.com/tcsst/

DOI: https://doi.org/10.36548/jtcsst.2020.2.003

\section{Performance Analysis}

Following the activities of the "Telecom Regulatory Authority of India" the proposed work was also periodically tested to observe number of call drops endured. The test results observed based on the feedback forms from the consumers proved that the proposed method enhanced the service quality and as well as the user satisfaction and minimized the billing cost. The flexibility in the proposed method minimized the dropped call rates as well as the capital and the maintenance expense. The figure. 3 and figure. 4 depicts the customer satisfaction and the total expenses after setting up the S-O network in the LTE.

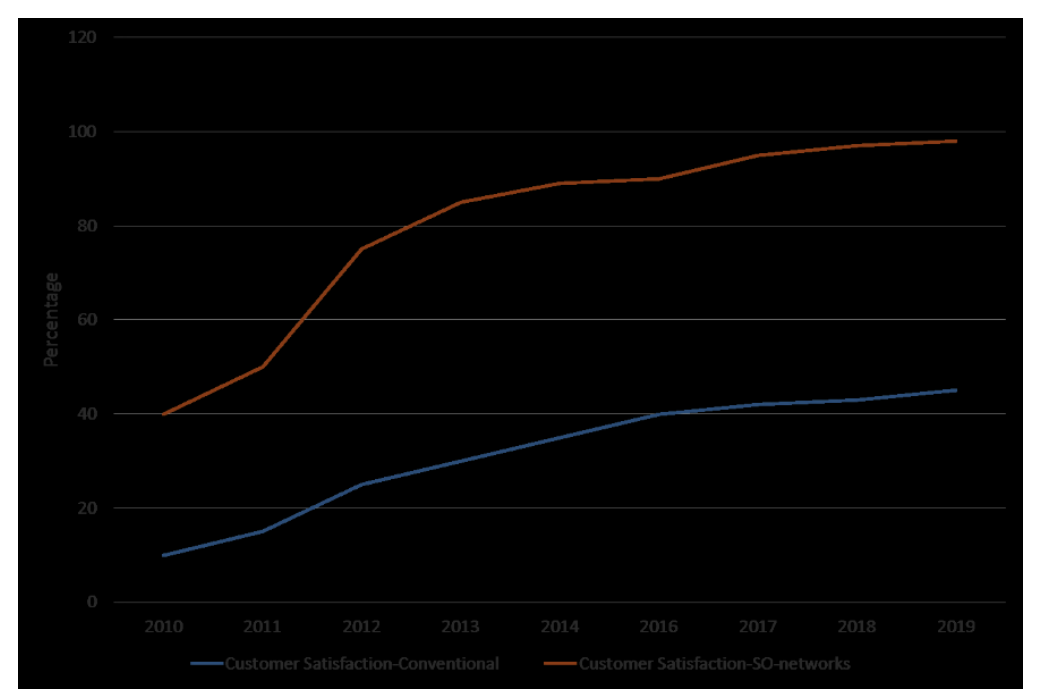

Figure.3 Customer Satisfaction

The traffic in the conveyance and the handover that were unsuccessful reduced by the setting up the Self organizing networks in the LTE (mobile network). The manual work was totally minimized and the operational capability was maximized. The human intervention was minimized, automatic optimization in handover, load balancing and the mobility management were accomplished taking in the appropriate optimization algorithm. The Self organizing networks heightened the revenue of the telecom services also, minimizing the total expenses as represented in the figure. 4

ISSN: 2582-4104 
Journal of trends in Computer Science and Smart technology (TCSST) (2020)

Vol.02/ No. 02

Pages: 89-97

https://www.irojournals.com/tcsst/

DOI: https://doi.org/10.36548/jtcsst.2020.2.003

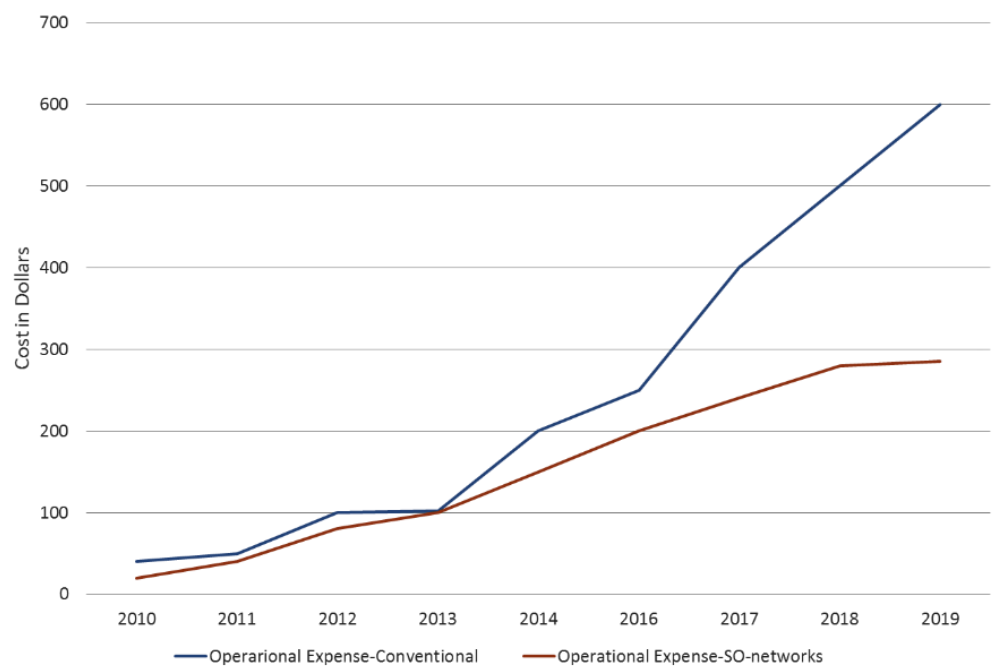

Figure.4 Operational Expense

\section{Conclusion}

To solve the issue in the telecom service related to the un-notified call termination taking place in the mobile networks. The paper bring out the reasons behind the call termination and devises the mechanism by configuring the self-organizing networks into the LTE. This enhances the service quality minimizing the call terminations and improving the voice quality. The periodical testing and the feed backs collected evinces the superior performance of the long term evolution- self organizing networks on the basis of the customer satisfaction and total expenses.

\section{References}

[1] http://164.100.47.193/Refinput/New_Reference_Notes/English/CALL_DROPS.pdf

[2] Shiokawa, Shigeki, and Michihiro Ishizaka. "Call admission scheme based on estimation of call dropping probability in wireless networks." In The 13th IEEE International Symposium on Personal, Indoor and Mobile Radio Communications, vol. 5, pp. 2185-2188. IEEE, 2002.

[3] Li, Xue Jun, and Peter Han Joo Chong. "A dynamic channel assignment scheme for TDMAbased multihop cellular networks." IEEE Transactions on Wireless Communications 7, no. 6 (2008): 1999-2003.

ISSN: 2582-4104 
Journal of trends in Computer Science and Smart technology (TCSST) (2020)

Vol.02/ No. 02

Pages: 89-97

https://www.irojournals.com/tcsst/

DOI: https://doi.org/10.36548/jtcsst.2020.2.003

[4] Balapuwaduge, Indika AM, Lei Jiao, Vicent Pla, and Frank Y. Li. "Channel assembling with priority-based queues in cognitive radio networks: Strategies and performance evaluation." IEEE transactions on wireless communications 13, no. 2 (2013): 630-645.

[5] Monica, C. H., and K. V. L. Bhavani. "A bandwidth degradation technique to reduce call dropping probability in mobile network systems." TELKOMNIKA Indonesian Journal of Electrical Engineering 16, no. 2 (2015): 303-307.

[6] Moysen, Jessica, and Lorenza Giupponi. "From 4G to 5G: Self-organized network management meets machine learning." Computer Communications 129 (2018): 248-268.

[7] Lobinger, Andreas, Szymon Stefanski, Thomas Jansen, and Irina Balan. "Coordinating handover parameter optimization and load balancing in LTE self-optimizing networks." In 2011 IEEE 73rd vehicular technology conference (VTC Spring), pp. 1-5. IEEE, 2011.

[8] Pandian, M. Durai. "Enhanced Network Selection and Handover Schema For Heterogeneous Wireless Networks." Journal of ISMAC 1, no. 01 (2019): 160-171.

[9] Smys, S., G. Josemin Bala, and Jennifer S. Raj. "Self-organizing hierarchical structure for wireless networks." In 2010 international conference on advances in computer engineering, pp. 268-270. IEEE, 2010.

[10] Smys, S., and G. Josemin Bala. "Stab-WIN: Self organized, topology control ability backbone node in wireless networks." Wireless Personal Communications 63, no. 3 (2012): 529-548

[11] Jyothirmai, Pondi, Jennifer S. Raj, and S. Smys. "Secured self organizing network architecture in wireless personal networks." Wireless Personal Communications 96, no. 4 (2017): 56035620 .

[12] Smys, S., Kamel A. Khaled, and Robert Bestak. "ACM/Springer Mobile Networks \& Applications (MONET) Guest Editorial for Special Issue on Innovative Computing Structures for Future Wireless Personal Networks." Mobile Networks and Applications 21, no. 3 (2016): 467.

[13] Smys, S. (2019). DDOS Attack Detection in Telecommunication Network Using Machine Learning. Journal of Ubiquitous Computing and Communication Technologies (UCCT), 1(01), $33-44$.

\section{Authors Biography}

Dr. M. Duraipandian is the Head of Department, in Department of Computer Science and Engineering, in Vivekanandha College of Technology for Women, Namakal, India. His interested area of research includes the Artificial Intelligence, Data Management and Data Mining, Computer Architecture, Computer Networks, Robotics, Pattern Recognition, Computer Vision, Software Systems, Distributed Computing, quantum computers, Computer Graphics

ISSN: 2582-4104 